\title{
Anxiety and new onset of cardiovascular disease: critical review and meta-analysis
}

Neeltje M. Batelaan, Adrie Seldenrijk, Mariska Bot, Anton J. L. M. van Balkom

and Brenda W. J. H. Penninx

\section{Background}

Anxiety has been associated with new-onset cardiovascular disease (CVD), but the quality of this relationship is unclear Only if anxiety is a causal, independent cardiovascular risk factor might it be a target for CVD prevention.

\section{Aims}

To determine and examine the independent association and causality between anxiety and incident CVD.

\section{Method}

PubMed, EMBASE and PsycINFO databases were searched up to October 2013. A review of Hill's criteria for causality and random effects meta-analysis were conducted of prospective, population-based studies examining anxiety and incident CVD in people free from CVD at baseline.

\section{Results}

The meta-analysis comprised 37 papers $(n=1565699)$.
The follow-up ranged from 1 to 24 years. Anxiety was associated with a $52 \%$ increased incidence of CVD (hazard ratio $=1.52,95 \% \mathrm{Cl} 1.36-1.71)$. The risk seemed independent of traditional risk factors and depression. The evaluation of Hill's criteria largely argued in favour of causality.

\section{Conclusions}

Anxiety may be of interest for CVD prevention. Future research should examine biological and behavioural underpinnings of the association in order to identify targets for intervention.

\section{Declaration of interest}

None.

\section{Copyright and usage}

(C) The Royal College of Psychiatrists 2016.
Cardiovascular disease (CVD) is a leading cause of morbidity and mortality, ${ }^{1}$ and its economic impact exceeds that of other diseases. $^{2}$ Substantial achievements have been made in the reduction of CVD mortality rates, by decreasing exposure to traditional risk factors such as smoking and hypertension. ${ }^{3-5}$ Researchers have argued that psychosocial factors are as important as traditional risk factors in preventing the onset of CVD. ${ }^{6}$ In a previous meta-analysis summarising 20 studies, anxiety was associated with a $26 \%$ increased risk of incident coronary heart disease (CHD), and a $48 \%$ increased risk of cardiac death, after adjustment for demographic and biological risk factors and health behaviours. $^{7}$ Since publication of that review in 2010, various new studies have been published; these justify an update of the previous meta-analysis. Several of the new studies examined anxiety disorders instead of self-reported anxiety symptoms, which is what the majority of earlier studies were based on. In addition, three aspects require a closer examination. First, the previous meta-analysis was restricted to $\mathrm{CHD} ;{ }^{7}$ inclusion of similar expressions of atherosclerotic vascular disease in the brain (stroke) or in the periphery (peripheral vascular disease) would provide a more complete picture of the association between anxiety and CVD. Second, since depression is highly comorbid with anxiety, ${ }^{8}$ and is associated with CVD onset and progression, ${ }^{9}$ it has to be ascertained whether anxiety is a true risk factor for CVD - independent of depression - by considering studies that explicitly adjust for or exclude co-occurring depression. The publication of new studies has allowed these analyses. Third, quantifying the association between anxiety and the onset of CVD does not corroborate a causal association. Ascertaining causality is essential when aiming to prevent CVD. In 1965 Hill formulated criteria for causality, ${ }^{10}$ but these had not been evaluated explicitly regarding the anxiety-CVD association. We conducted a meta-analysis of prospective population-based studies in persons free from CVD to examine whether anxiety (anxiety disorder or increased anxiety symptoms) was associated with the onset of atherosclerotic CVD, compared with no anxiety (no anxiety disorder or no/minimal anxiety symptoms). ${ }^{11}$ Secondary outcomes included CHD, myocardial infarction, stroke and cardiovascular mortality. Moreover, we reviewed whether Hill's criteria for causality were being met, by conducting relevant subgroup analyses and qualitatively reviewing additional literature.

\section{Method}

We searched without language restrictions in PubMed, EMBASE and PsycINFO (from inception up to 28 October 2013) for prospective population-based studies that examined whether anxiety (anxiety disorder or increased anxiety symptoms) was associated with the new onset of atherosclerotic CVD, relative to no anxiety (no anxiety disorder or no/minimal anxiety symptoms) in humans free from CVD. In these searches we combined words indicating anxiety, CVD and prospective design. Both text and keywords were used (see online supplement DS1).

Two raters (N.M.B. and A.S.) independently screened titles and abstracts and assessed for eligibility the full text of part of the studies. The following inclusion criteria were applied:

(a) longitudinal design, with the anxiety assessment prior to assessment of CVD;

(b) assessment of new-onset atherosclerotic CVD (studies not excluding participants with CVD at baseline were allowed if adjusted for baseline CVD status);

(c) comparison of CVD risk between individuals with and without anxiety.

The assessment of anxiety could be based on self-reporting of symptoms, a clinical diagnostic assessment or registration in a managed care database. Consequently, both anxiety symptoms and anxiety disorders were included. Atherosclerotic CVD 
included CHD, myocardial infarction, ischaemic heart disease, cardiovascular mortality, sudden cardiac death, stroke and peripheral arterial disease, or a combination of these end-points. As differentiation between angina pectoris and non-cardiac chest pain might be difficult, angina was not included in our definition of CVD, yet allowed when part of a broader outcome definition. Likewise, we restricted the analyses to atherosclerotic CVD, yet allowed heart failure when part of a broader outcome definition. Articles not presenting original data or consisting only of abstracts were excluded. If multiple papers reported similar outcomes based on the same data-set, we chose the study with the largest sample or longest follow-up interval. Consensus was reached in cases of initial disagreement.

\section{Data extraction}

Three authors (N.M.B., M.B. and A.S.) independently extracted descriptive information from each study using a predesigned collection form. This information included characteristics of the study population (gender, mean age, age range), publication year, study location (continent), follow-up duration, anxiety measurement, type of CVD outcome, CVD status at baseline, covariate adjustment, baseline depression status and effect sizes with confidence intervals. If a single study reported several anxiety measures, we included the dimension that best reflected general psychological anxiety. If anxiety was classified into more than two categories, the category with highest anxiety was compared with the category with lowest anxiety. Meta-analyses were performed for the main outcome (CVD) and performed separately for the predefined secondary outcomes. If studies examined multiple outcomes in the same data-set, the broadest was used as the main outcome. If applicable, other outcomes were allowed to be included in a meta-analysis of secondary outcomes. Studies could therefore be included in more than one meta-analysis. If risk estimates were provided for subgroups (for example, men and women), associations are reported for these subgroups with their corresponding sample sizes.

\section{Risk of bias}

Studies may differ in quality, which may bias results. To assess the risk of bias, all studies were scored for six domains relevant to prognostic studies: ${ }^{12}$ study participation, study attrition, prognostic factor measurement, outcome measurement, confounding, statistical analysis and reporting. A summary score was computed (online Table DS1).

\section{Statistical analysis}

Meta-analyses were performed for the main outcome of CVD to assess whether anxiety increases risk irrespective of the location in the body and also to find secondary outcomes (CHD, myocardial infarction, stroke, cardiovascular mortality, peripheral vascular disease). Hazard ratios (HRs) were used as the common measure of associations; relative risks (RRs) and odds ratios (ORs) were considered equivalent. Since we expected considerable heterogeneity across studies, HRs were pooled using the random effects model. Forest plots were produced to enable visual assessment of the HRs and corresponding 95\% confidence intervals. Heterogeneity of HRs was evaluated by the Cochrane $Q$ statistic and the $I^{2}$ statistic. ${ }^{13}$ The possibility of publication bias was evaluated using the Egger test of the intercept and visual inspection of a funnel plot. ${ }^{14}$ The Duval \& Tweedie non-parametric trim and fill procedure was used to adjust for publication bias. ${ }^{15}$ For the main outcome the risk of bias across studies was further explored by removing one study at a time and reanalysing the remaining data-set. Additionally, we investigated the influence of selected characteristics on the pooled estimate for CVD. Prespecified subgroup analyses were conducted for the following categorical variables: gender; age group (mean age of cohort $<55$ years, $\geqslant 65$ years, 'other'); continent (North America, Europe, Asia); anxiety type (general, panic, post-traumatic stress); anxiety severity (disorder $v$. symptoms); sample CVD-free at baseline (yes $v$. no, but adjusted for baseline CVD); adjustment for gender, age and at least one other traditional CVD risk factor such as smoking, physical activity, hypertension, body mass index (yes $v$. no); and exclusion of people with depression or adjustment for co-occurring depression (yes $v$. no). For the age group variable, if the mean age was not reported the age range was used, and if this could not be classified into $<55$ or $\geqslant 65$ years it was classified as 'other'. Meta-regression was used to study the impact of the continuous characteristics duration of follow-up, year of publication and study quality on the pooled estimates. All analyses were performed with Comprehensive Meta-Analysis version 2.2.064. ${ }^{16}$

\section{Criteria of causality}

Hill's criteria of causality include strength, consistency, specificity, temporality, biological gradient, plausibility, coherence, experiment and analogy (online Table DS2). The more criteria that are met, the more likely it is that an association is causal. We used these criteria to examine the likelihood of causality in the association between anxiety and new-onset CVD. ${ }^{10}$ Several of these criteria can be evaluated by the results of the meta-analysis and corresponding subgroup analyses. Other criteria require a qualitative review of the literature, for which we additionally searched for relevant studies (Table DS2).

\section{Results}

The literature search resulted in 2489 records (Fig. 1). Of these, 86 full-text articles were assessed for eligibility. Nine studies were excluded because they used the same data-set with similar outcomes, but with smaller sample sizes or shorter follow-up periods, ${ }^{17-23}$ two of which were also in Russian. ${ }^{24,25}$ Three authors provided measures of association on request ${ }^{26-28}$ three studies were excluded because a continuous anxiety measure was used and dichotomised associations were not provided. ${ }^{29-31}$ In total, 37 papers were included reporting 62 comparisons (online Table DS3). All of these papers were published between 1991 and 2013. The number of participants per study ranged from 506 to 404643 , and the average follow-up ranged from 1 year to 24 years. Nine studies assessed anxiety diagnoses and 25 studies assessed anxiety symptoms. In two studies, estimates were provided only for subgroups of participants: in one, the sample was restricted to women, ${ }^{32}$ and in the other to people of Black ethnicity. ${ }^{33}$ Only one study addressed peripheral arterial disease $;^{34}$ a separate meta-analysis was thus not possible for this outcome.

\section{Meta-analyses}

Pooled analysis revealed that anxiety was associated with a $52 \%$ increased incidence of CVD ( $\mathrm{HR}=1.52,95 \%$ CI 1.36-1.71) based on a total of 1565699 persons (Fig. 2). We detected strong evidence of heterogeneity $\left(Q=483.7, \quad P<0.001 ; I^{2}=92.1\right) .{ }^{13}$ Subsequent removal of each study from the analyses had little impact on the overall estimate, except for elimination of Gomez-Caminero et al's data, ${ }^{35}$ which gave a pooled HR of 1.44 (95\% CI 1.33-1.57) and reduced the heterogeneity $(Q=124.5$, $\left.P<0.001 ; I^{2}=70.3\right)$. Egger's test for publication bias was significant (one-tailed $P=0.03$ ), indicating that publication bias 


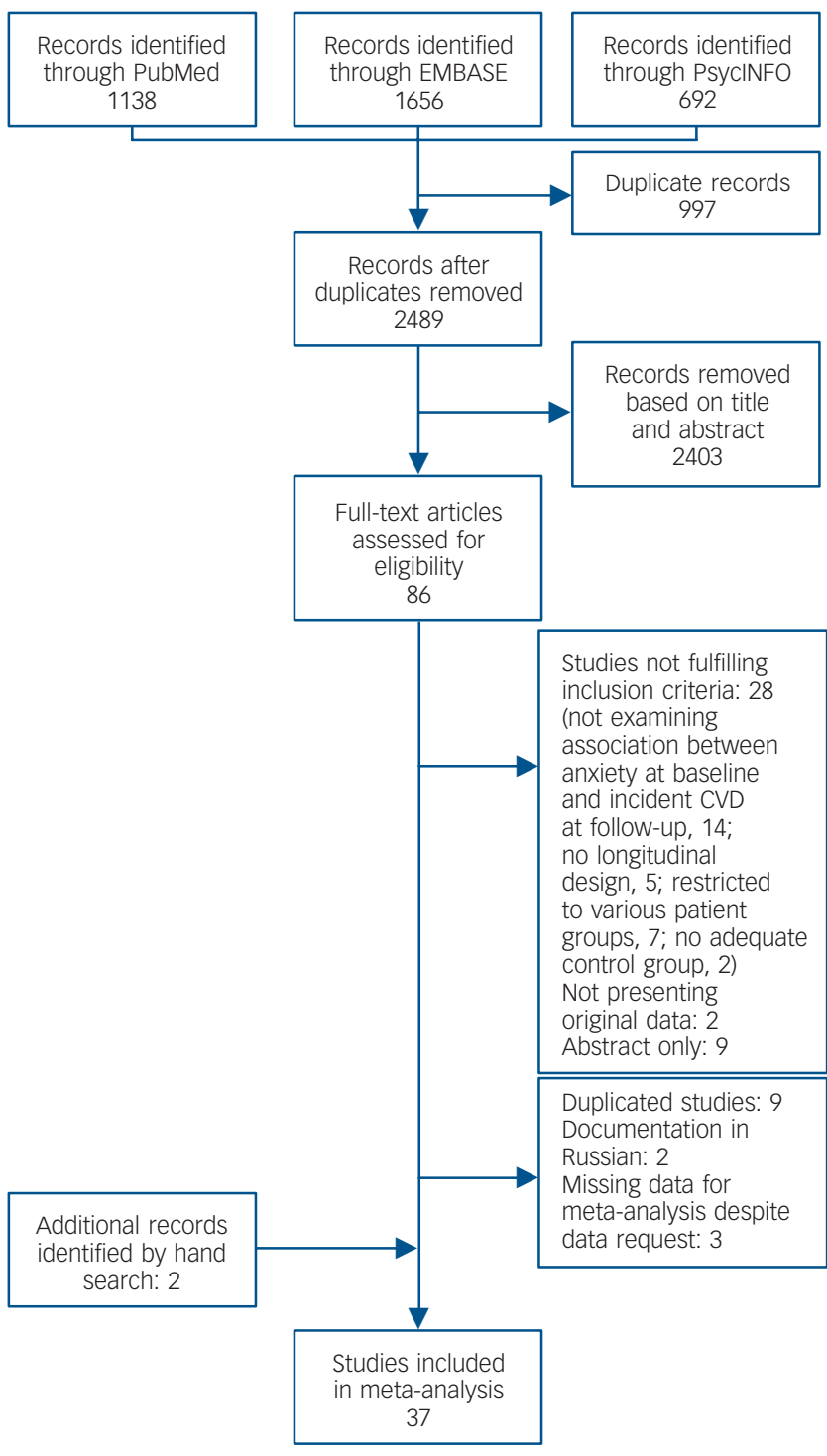

Fig. 1 Selection of studies.

was likely (online Fig. DS1). After adjustment for publication bias the pooled HR dropped $21 \%$ but remained significant $(\mathrm{HR}=1.41$, 95\% CI 1.26-1.57). Anxiety was also significantly related to all secondary outcomes, with HRs varying from 1.38 for myocardial infarction (95\% CI $1.16-1.64)$ to 1.74 for stroke (95\% CI $1.25-$ 2.43) (Table 1). Thus, anxiety increased the risk of atherosclerotic CVD irrespective of its location in the body. Publication bias was likely for all outcomes except myocardial infarction (Egger's tests of the intercept one-tailed $P$-values for myocardial infarction,
CHD, cardiovascular mortality and stroke were $0.12,0.03$, $<0.001$ and 0.05 respectively). Adjustment for publication bias reduced the strength of the associations but they remained significant (data not shown). None of the subgroup analyses or meta-regression analyses demonstrated any difference in size of the association between anxiety and new-onset CVD (Table 2). Results are therefore consistent across studies examining anxiety symptoms and disorders, and across studies that considered co-occurring depression and those that did not.

\section{Causality criteria}

Strength

The strength of associations varied widely between studies (Fig. 2). The pooled HR for people with anxiety to develop CVD was 1.52 (95\% CI 1.36-1.71). After taking publication bias into account this ratio attenuated to 1.41 (95\% CI 1.26-1.57). This risk estimate might be an overestimation because confounders were insufficiently accounted for: for example, only a third of studies adjusted for comorbid depression, which is regarded as a CVD risk factor, ${ }^{9}$ and only a minority of studies adjusted for psychotropic medication, which some have associated with increased cardiovascular risk. ${ }^{36-39}$ Some confounders were only assessed globally, and changes in exposure to confounders over time were almost never accounted for, although they might have influenced the association (see post-hoc analysis). ${ }^{40}$ The presence of depression at a later time particularly requires attention, since depression may develop as a comorbid condition thus complicating anxiety. Contrarily, since the exact pathways by which anxiety causes CVD are unknown, risk estimates might be underestimated because confounding variables such as hypertension or dyslipidaemia could have been mediators. Results of the meta-analyses, however, indicate that anxiety is an independent risk factor, because risk estimates from studies that accounted for depression (14 comparisons; $\mathrm{HR}=1.57,95 \%$ CI 1.29-1.90) or multiple CVD risk factors (34 comparisons; $\mathrm{HR}=1.50,95 \%$ CI 1.33-1.71) were comparable with the pooled HR.

\section{Consistency}

Studies to date are heterogeneous regarding gender and age of population, country of investigation, duration of follow-up and year of publication (Table DS3). However, these characteristics did not significantly modify the association between anxiety and new-onset CVD (Tables 2 and 3), indicating that this association is rather consistent. In contrast to previous results, ${ }^{41}$ we found the association between anxiety and new-onset CVD to be similar for all anxiety types.

\section{Specificity}

Anxiety has been associated with various somatic diseases in both cross-sectional and longitudinal studies. ${ }^{42-45}$ We found an

\begin{tabular}{|c|c|c|c|c|c|}
\hline & No. of papers/comparisons & Pooled HR $(95 \% \mathrm{Cl})$ & $Q$ & $1^{2}$ & d.f. \\
\hline \multicolumn{6}{|l|}{ Primary outcome } \\
\hline CVD & $35 / 39$ & $1.52(1.36-1.71)$ & 483.7 & 92.1 & 38 \\
\hline \multicolumn{6}{|l|}{ Secondary outcomes } \\
\hline $\mathrm{CHD}$ & $26 / 29$ & $1.49(1.31-1.69)$ & 468.7 & 94.0 & 28 \\
\hline Myocardial infarction & $11 / 12$ & $1.38(1.16-1.64)$ & 92.3 & 88.1 & 11 \\
\hline Stroke & $7 / 7$ & $1.74(1.25-2.43)$ & 17.6 & 65.8 & 6 \\
\hline CVD mortality & $14 / 14$ & $1.61(1.22-2.12)$ & 62.9 & 79.3 & 13 \\
\hline
\end{tabular}




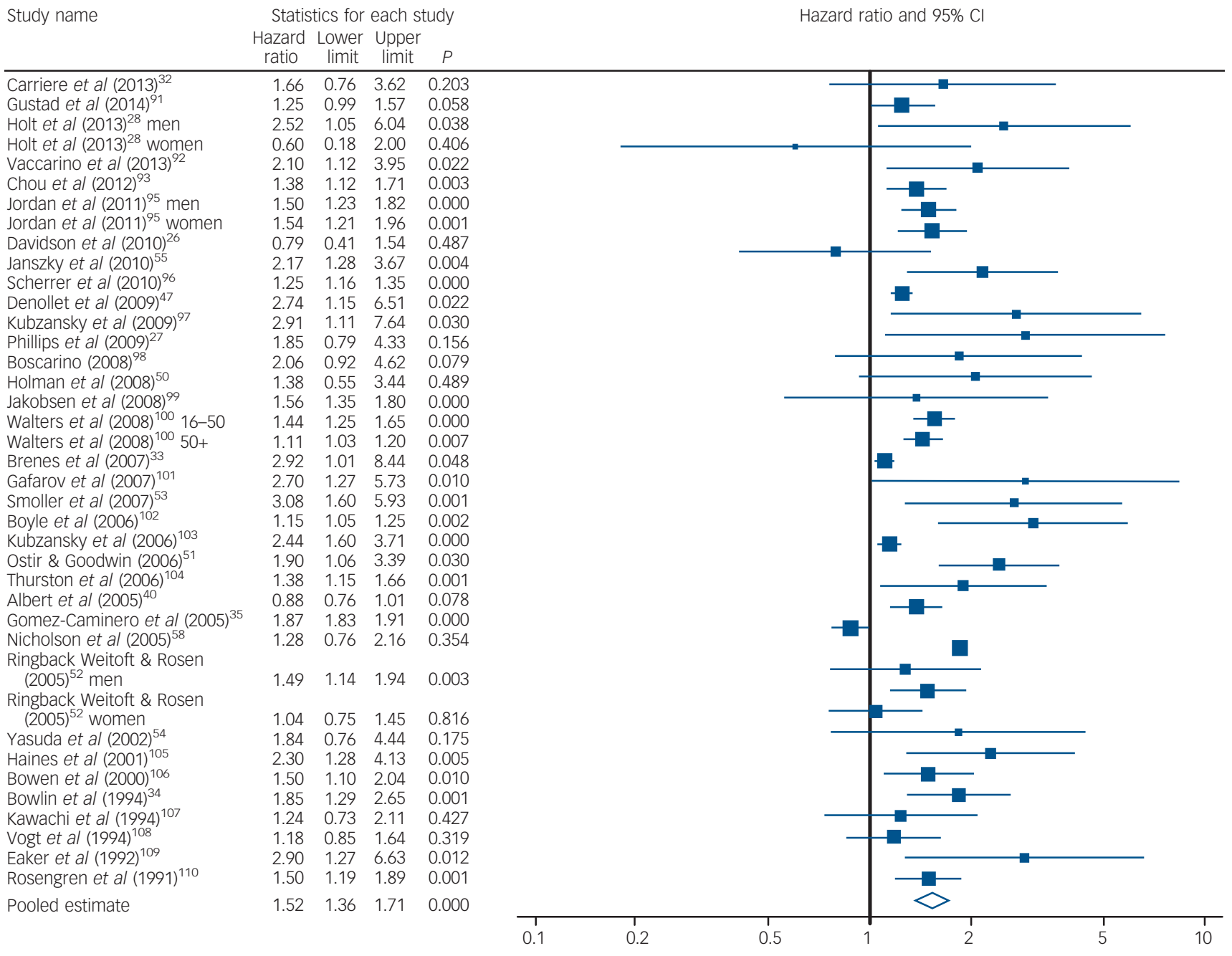

Fig. 2 Forest plot.

association between anxiety and cardiovascular mortality, whereas previous studies showed mixed results for associations between anxiety and overall mortality. ${ }^{46-49}$ However, as acknowledged by Hill, a less than highly specific association can still reflect causality. For example, a possible hypothesis is that anxiety causes dysregulation of homoeostatic mechanisms, which may result in inflammation (i.e. a specific result), and contribute to the development of various somatic diseases.

\section{Temporality}

To ascertain that anxiety precedes CVD, associations must be prospectively studied in CVD-free participants. Exclusion of studies that adjusted for pre-existing CVD did not alter the risk estimates $\left(\mathrm{HR}=1.50,95 \%\right.$ CI $1.32-1.70$; see Table 2). ${ }^{27,32,33,49-54}$ However, exclusion of people with CVD at baseline cannot rule out the presence of subclinical CVD, by which causation in the opposite direction remains an option. Stronger evidence for a temporal relationship running from anxiety to CVD came from one study. It followed a young cohort - in which the presence of subclinical CVD is unlikely - for 37 years, and found anxiety to be associated with incident CVD. ${ }^{55}$ Still, low cardiovascular fitness at age 18 years in the absence of subclinical CHD might advance the onset of depression in later years. ${ }^{56}$ De Jonge \& Roest postulated a bidirectional hypothesis between depression and CVD, i.e. 'mutually reinforcing disorders.. ${ }^{57}$ Additionally, an unknown underlying factor might cause both anxiety and (probably at a slower pace) CVD, for example a common genetic vulnerability. To our knowledge, this latter hypothesis has not yet been examined.

\section{Biological gradient}

If causal, higher exposure to anxiety (i.e. greater severity, longer duration) increases the CVD risk. Risk estimates for anxiety disorders (9 studies; $\mathrm{HR}=1.60,95 \%$ CI 1.32-1.94) v. symptoms (25 studies; HR $=1.44,95 \%$ CI $1.30-1.60$ ) were higher, but not significantly so (Table 2). Thus, clear evidence for a biological gradient is lacking. In the reviewed papers, a dose-response relationship based on anxiety duration was globally investigated by Nicholson et $a l,{ }^{58}$ who stratified the risk of CHD events across those with former, persistent or new distress or anxiety. Their results did not support a biological gradient either. A more detailed assessment on the amount of exposure, for example with anxiety assessed on a continuous scale, or with life chart interviews assessing duration and severity of anxiety over time, might be needed to reveal a biological gradient, if present.

\section{Plausibility}

The leading cause of CVD is atherosclerosis, which can be enhanced both indirectly by behavioural factors and directly by 


\begin{tabular}{|c|c|c|c|c|c|c|}
\hline & No. of comparisons & Pooled HR (95\% Cl) & Q & $1^{2}$ & d.f. & $\begin{array}{l}P \text { between } \\
\text { subgroups }\end{array}$ \\
\hline Gender & & & & & & 0.346 \\
\hline Men and women & 15 & $1.40(1.19-1.66)$ & 290.4 & 95.2 & 14 & \\
\hline Women & 9 & $1.58(1.12-2.23)$ & 41.8 & 80.9 & 8 & \\
\hline Men & 15 & $1.66(1.42-1.96)$ & 41.1 & 65.9 & 14 & \\
\hline Age groups & & & & & & 0.090 \\
\hline$<55$ years & 19 & $1.47(1.25-1.73)$ & 160.8 & 88.8 & 18 & \\
\hline$\geqslant 65$ years & 7 & $2.04(1.48-2.79)$ & 6.5 & 8.05 & 6 & \\
\hline Other & 13 & $1.40(1.26-1.56)$ & 50.7 & 76.4 & 12 & \\
\hline Continent & & & & & & 0.561 \\
\hline Asia & 4 & $1.65(1.28-2.13)$ & 4.3 & 30.7 & 3 & \\
\hline Europe & 14 & $1.43(1.25-1.63)$ & 43.3 & 70.0 & 13 & \\
\hline North America & 21 & $1.54(1.30-1.81)$ & 324.0 & 93.8 & 20 & \\
\hline Anxiety from managed care database & & & & & & 0.385 \\
\hline No & 31 & $1.56(1.37-1.76)$ & 99.0 & 69.7 & 30 & \\
\hline Yes & 8 & $1.40(1.14-1.72)$ & 270.1 & 97.4 & 7 & \\
\hline Anxiety type ${ }^{a}$ & & & & & & 0.925 \\
\hline General & 25 & $1.52(1.36-1.70)$ & 59.3 & 59.5 & 24 & \\
\hline Panic & 5 & $1.55(1.15-2.10)$ & 184.3 & 97.8 & 4 & \\
\hline PTSD & 7 & $1.47(1.25-1.72)$ & 11.0 & 45.4 & 6 & \\
\hline Anxiety disorder & & & & & & 0.357 \\
\hline No & 30 & $1.44(1.30-1.60)$ & 104.8 & 72.3 & 29 & \\
\hline Yes & 9 & $1.60(1.32-1.94)$ & 113.1 & 92.9 & 8 & \\
\hline Free from CVD at baseline & & & & & & 0.568 \\
\hline No, but adjusted & 9 & $1.62(1.27-2.06)$ & 12.1 & 33.6 & 8 & \\
\hline Yes & 30 & $1.50(1.32-1.70)$ & 470.1 & 93.8 & 29 & \\
\hline Adjusted for CVD risk factors additional to gender and age & & & & & & 0.611 \\
\hline No & 5 & $1.58(1.37-1.82)$ & 4.3 & 6.3 & 4 & \\
\hline Yes & 34 & $1.50(1.33-1.71)$ & 478.4 & 93.1 & 33 & \\
\hline Adjusted for depression & & & & & & 0.575 \\
\hline Adjusted/excluded & 14 & $1.57(1.29-1.90)$ & 274.6 & 95.3 & 13 & \\
\hline Unadjusted & 25 & $1.47(1.30-1.65)$ & 81.3 & 70.5 & 24 & \\
\hline
\end{tabular}

\section{Table 3 Meta-regression for the primary outcome ${ }^{a}$}

\begin{tabular}{|lccc|}
\hline & No. of papers/comparisons & B (95\% Cl) & $P$ \\
\hline Duration of follow-up & $35 / 39$ & $0.0103(-0.0084$ to 0.0267$)$ & 0.22 \\
\hline Year of publication & $35 / 39$ & $-0.0020(-0.0211$ to 0.0171$)$ & 0.84 \\
\hline Quality & $35 / 39$ & $-0.0386(-0.1134$ to 0.0362$)$ & 0.31 \\
\hline a. Meta-regression was performed using moments of methods in Comprehensive Meta-analysis 2. & & \\
\hline
\end{tabular}

physiological processes. Some evidence exists that these proatherogenic factors are associated with anxiety. For example, anxiety disorders have been associated with smoking, lower physical activity and poor diet. ${ }^{59-61}$ In addition, anxiety has been associated with metabolic abnormalities such as increased cholesterol levels and hypertension. ${ }^{62,63}$ Activation of the immune system has also been related to anxiety, ${ }^{64}$ as has a hypercoagulable state. $^{65}$ Regarding hypothalamic-pituitary-adrenal (HPA) axis functioning, evidence is ambiguous. ${ }^{66,67}$ Furthermore, anxiety is thought to be marked by an aberrant autonomic heart control with elevated sympathetic activity, ${ }^{68}$ although this might be driven by antidepressants. ${ }^{69}$ In summation, various pro-atherogenic factors are more frequently found in individuals with anxiety, which concurs with the currently accepted understanding of pathophysiological processes in CVD.

\section{Coherence}

Data from animal studies could provide material for the coherence criterion, although studies examining anxiety and CVD are lacking. However, some animal studies have investigated stress-related social factors in association with pathophysiological processes leading to CVD. A review of 14 studies among monkeys concludes that there is some evidence for an association between stress due to disruption of dominance hierarchy and coronary atherosclerosis. ${ }^{70}$ Another study in monkeys found that social separation led to altered autonomic activity (higher heart rates), which may exacerbate atherosclerosis. ${ }^{71}$ A study of mice found that highly anxious mice showed greater chronic stress burden (corticosterone levels) and suppressed protective immunity (levels of inflammatory agents) than mice with low anxiety levels. ${ }^{72}$ In summation, there is some indication for the criterion of coherence, but convincing evidence is lacking.

\section{Experiment}

Primary prevention studies investigating whether effective anxiety treatment indeed prevents CVD onset have not been conducted, and would present quite a challenge. Some small studies that investigated the effect of anxiety treatment on the postulated biological pathways have observed potential cardioprotective effects. For example, treatment with selective serotonin reuptake 
inhibitors (SSRIs) normalised HPA axis dysregulation, ${ }^{73}$ and biofeedback, cognitive-behavioural therapy and/or antidepressant medication improved autonomic nervous system functioning. ${ }^{74-76}$ In contrast, antidepressants have also been shown to impair autonomic nervous system activity. ${ }^{69,77}$ Moreover, whether effects on biomarkers can be translated to the onset of CVD remains to be seen. Studies investigating the prevention of cardiovascular events by treating anxiety in patients with CVD (i.e. secondary prevention) have not been carried out either. Such studies sound appealing to start with because of the well-defined high-risk group. However, it is unknown whether the underlying pathogenic mechanisms of anxiety are similar in people with or without CVD. In addition, for depression, a few large-scale secondary prevention studies have generally found no evidence that the treatment of depression improves cardiac outcome. ${ }^{78}$ The authors expounded on these disappointing results by arguing that effect sizes of antidepressant treatment were too low to expect cardioprotective effects. In line with this argument, secondary analyses have shown that people who do not respond to antidepressant treatment are particularly highly at risk of adverse CVD outcomes. ${ }^{79,80}$

\section{Analogy}

Other psychosocial factors have been postulated to increase the risk of CVD. Whereas the association between hostility and cardiovascular functioning appeared to be mainly driven by covariates, ${ }^{81}$ the adjusted HR for depression and CVD onset was $1.81 .^{9}$ Although we consider depression to be an analogous case, interpretation of the depression-CVD association is, like the anxiety-CVD association, hampered by publication bias, the possibility of reverse causation and residual confounding.

\section{Discussion}

A total of 37 studies, with 1565699 participants, were included in the meta-analysis on anxiety and CVD. This is almost twice the number of studies included in the previous meta-analysis focusing on $\mathrm{CHD},{ }^{7}$ thereby justifying an update. Anxiety significantly increased the hazard ratio for incident atherosclerotic CVD by $52 \%$. Although there was evidence of publication bias, imputing potentially missing studies resulted in an HR of 1.41 for the onset of CVD. The association between anxiety and new-onset CVD thereby appears to be at least of similar strength to that between well-established risk factors and CVD. For example, meta-analytic data have shown that the adjusted RRs for CVD associated with moderate overweight and obesity were 1.17 (95\% CI 1.11-1.23) and 1.49 (95\% CI 1.32-1.67) respectively, ${ }^{82}$ and that the metabolic syndrome is associated with an increased risk of cardiovascular events or death (adjusted pooled $\mathrm{RR}=1.54$, 95\% CI 1.321.79). ${ }^{83}$ In addition, a high level of physical activity protected against CVD both in men (pooled $\mathrm{RR}=0.76,95 \%$ CI $0.70-0.82$ ) and in women (pooled $\mathrm{RR}=0.73,95 \%$ CI $0.68-0.78$ ) ${ }^{84}$

In the introduction we mentioned three aspects requiring additional research. First, it was unknown whether anxiety induces vascular abnormalities independent of their localisation along the arterial tree: in the brain (stroke), the heart (CHD, myocardial infarction) or the periphery. We therefore included all outcomes of atherosclerotic vascular disease. Anxiety increased the risk of all secondary outcomes (CHD, myocardial infarction, cardiovascular mortality, stroke); there is therefore no reason to assume that different mechanisms are causing CVD in specific locations only. Peripheral vascular disease was not investigated as a secondary outcome, since this category included only one study. Further research is needed to verify the risk of new-onset peripheral vascular disease associated with anxiety. Second, the extent to which anxiety increases CVD risk, independent of co-occurring depression, required further research. Unlike previous research, the 14 studies in our meta-analysis adjusted for comorbid depression or excluded people with depression. Subgroup analyses based on whether studies considered co-occurring depression revealed similar risk estimates, indicative of the independence of anxiety as a cardiovascular risk factor. However, depression occurring at a later time has not been assessed in studies to date, and could not be considered. The risk estimate for anxiety in our meta-analysis was not very different from the one in the metaanalysis for depression (e.g. Nicholson et al), ${ }^{9}$ suggesting that the effects of anxiety and depression are comparable. Results thus underline the need to adjust for anxiety when examining the impact of depression. As most studies on depression have not included anxiety as a covariate, the impact of depression may even have been overestimated (e.g. Nicholson et al). ${ }^{9}$ In the light of all studies examining psychosocial factors and the onset of CVD, one might argue that, rather than anxiety or depression, a non-specific 'umbrella' factor such as general distress, neuroticism or negative affect accounts for the increased risk of CVD. Third, criteria for causal inference in the anxiety-CVD association had not previously been systematically evaluated. We used the meta-analysis, several subgroup analyses and an additional critical review of the literature to evaluate whether Hill's criteria for causality were met. Results to date largely argue in favour of a causal relationship. However, there is no clear evidence yet for coherence, analogy, a biological gradient or experimental data.

\section{Strengths and limitations}

An important strength of this study is the integration of a quantitative summary (meta-analysis) and a qualitative assessment (application of Hill's criteria for causality). Several limitations should be acknowledged as well. First, a high degree of heterogeneity was observed in the studies included. We pooled studies that differed in sample characteristics, anxiety assessment, CVD outcome assessment and statistical analysis. Subgroup analyses, however, suggested that the pooled estimates between these characteristics did not differ. Second, we restricted our analyses to atherosclerotic CVD, therefore no conclusion can be provided with respect to (for example) heart failure. Third, studies differed in the extensiveness of adjustment to covariates and the accuracy by which covariates were measured. This was addressed in the assessment of bias. Meta-regression analysis of the risk of bias scores was not significant.

\section{Study implications}

Anxiety may be a point of particular interest for the prevention of CVD incidence. Anxiety is associated with an increased risk of CVD, and this risk appears to be independent of traditional risk factors and depression. In addition, its magnitude is comparable with that of traditional risk factors. Moreover, the prevalence of anxiety disorders and symptoms is high, ${ }^{85-88}$ effective treatments reducing the exposure to anxiety as a risk factor are available, ${ }^{89}$ and there is significant potential to increase the number of people being treated. ${ }^{90}$ Applying Hill's criteria, our study largely argues in favour of causality, but has revealed important gaps in knowledge, particularly experimental evidence. Deriving experimental evidence from primary prevention studies would present quite a challenge. To begin with, secondary prevention studies might be more feasible. However, before embarking on large-scale experimental programmes it seems sensible to examine in more detail the biological and behavioural underpinnings of the association between anxiety and CVD. By doing so, targets for 
intervention might be identified that would decrease anxiety and subsequently the magnitude of the worldwide CVD health problem. Until such time that a better insight is gained into the underlying mechanisms, the best advice appears to be to focus on general (behavioural) cardiovascular risk reduction in high-risk populations. As to the primary target of risk intervention, the American Heart Association has stated that 'adoption of healthy life habits remains the cornerstone of primary prevention.' ${ }^{111}$

Neeltje M. Batelaan, MD, PhD, Adrie Seldenrijk, PhD, Mariska Bot, PhD,

Anton J. L. M. van Balkom, MD, PhD, Brenda W. J. H. Penninx, PhD, Department of Psychiatry and EMGO Institute for Health and Care Research, VU University Medica Centre, Amsterdam, The Netherlands

Correspondence: Dr Neeltje M. Batelaan, Department of Psychiatry VU University Medical Center, A.J. Ernststraat 1187, 1081 HL Amsterdam, The Netherlands. Email: n.batelaan@ggzingeest.nl

First received 21 Aug 2014, final revision 26 Mar 2015, accepted 24 Apr 2015

\section{Funding}

B.W.J.H.P. is supported by an NWO-VICI grant 91811602

\section{Acknowledgements}

We thank Caroline Planting of the VU University library for her help with the literature search. We also thank our colleague researchers Richard Holt, Anna Phillips and Karina Davidson for providing additional information regarding their studies.

\section{References}

1 Mathers CD, Loncar D. Projections of global mortality and burden of disease from 2002 to 2030. PLOS Med 2006; 3: e442.

2 Roger VL, Go AS, Lloyd-Jones DM, Benjamin EJ, Berry JD, Borden WB, et al. Heart disease and stroke statistics - 2012 update: a report from the American Heart Association. Circulation 2012; 125: e2-220.

3 Ford ES, Ajani UA, Croft JB, Critchley JA, Labarthe DR, Kottke TE, et al. Explaining the decrease in U.S. deaths from coronary disease, 1980-2000. N Engl J Med 2007; 356: 2388-98.

4 Unal B, Critchley JA, Capewell S. Explaining the decline in coronary heart disease mortality in England and Wales between 1981 and 2000. Circulation 2004; 109: 1101-7.

5 Vartiainen E, Laatikainen T, Peltonen M, Juolevi A, Mannisto S, Sundvall J, et al. Thirty-five-year trends in cardiovascular risk factors in Finland. Int $J$ Epidemiol 2010; 39: 504-18.

6 Yusuf S, Hawken S, Ounpuu S, Dans T, Avezum A, Lanas F, et al. Effect of potentially modifiable risk factors associated with myocardial infarction in 52 countries (the INTERHEART study): case-control study. Lancet 2004; 364 937-52.

7 Roest AM, Martens EJ, de Jonge P, Denollet J. Anxiety and risk of incident coronary heart disease: a meta-analysis. J Am Coll Cardiol 2010; 56: 38-46.

8 Lamers F, van Oppen P, Comijs HC, Smit JH, Spinhoven P, van Balkom AJ, et al. Comorbidity patterns of anxiety and depressive disorders in a large cohort study: the Netherlands Study of Depression and Anxiety (NESDA). J Clin Psychiatry 2011; 72: 341-8.

9 Nicholson A, Kuper $\mathrm{H}$, Hemingway $\mathrm{H}$. Depression as an aetiologic and prognostic factor in coronary heart disease: a meta-analysis of 6362 events among 146538 participants in 54 observational studies. Eur Heart J 2006; 27 2763-74.

10 Hill BA. The environment and disease: association or causation? Proc Roy Soc Med 1965; 58: 295-300.

11 Moher D, Liberati A, Tetzlaff J, Altman DG; PRISMA Group. Preferred reporting items for systematic reviews and meta-analyses: the PRISMA statement. PLOS Med 2009; 6: e1000097.

12 Hayden JA, Cote $\mathrm{P}$, Bombardier $\mathrm{C}$. Evaluation of the quality of prognosis studies in reviews. Ann Intern Med 2006; 144: 427-37.

13 Higgins JP, Thompson SG, Deeks JJ, Altman DG. Measuring inconsistency in meta-analyses. BMJ 2003; 327: 557-60.

14 Egger M, Smith GD, Schneider M, Minder C. Bias in meta-analysis detected by a simple, graphical test. $B M J 1997 ; 315$ : 629-34.
15 Duval S, Tweedie R. Trim and fill: a simple funnel-plot-based method of testing and adjusting for publication bias in meta-analysis. Biometrics 2000; 56: $455-63$.

16 Biostat. Comprehensive Meta-Analysis, version 2.2.064. Biostat.

17 Chen $\mathrm{YH}, \mathrm{Hu} \mathrm{CJ}$, Lee $\mathrm{HC}$, Lin $\mathrm{HC}$. An increased risk of stroke among panic disorder patients: a 3-year follow-up study. Can J Psychiatry 2010; 55: 43-9.

18 Boscarino JA. Psychobiologic predictors of disease mortality after psychological trauma: implications for research and clinical surveillance. J Nerv Ment Dis 2008; 196: 100-7.

19 Shen BJ, Avivi YE, Todaro JF, Spiro A, Laurenceau JP, Ward KD, et al. Anxiety characteristics independently and prospectively predict myocardial infarction in men the unique contribution of anxiety among psychologic factors. J Am Coll Cardiol 2008; 51: 113-9.

20 Kubzansky LD, Kawachi I, Spiro A, Weiss ST, Vokonas PS, Sparrow D. Is worrying bad for your heart? A prospective study of worry and coronary heart disease in the Normative Aging Study. Circulation 1997; 95: 818-24.

21 Kawachi I, Sparrow D, Vokonas PS, Weiss ST. Symptoms of anxiety and risk of coronary heart disease. The Normative Aging Study. Circulation 1994; 90 : $2225-9$

22 Haines AP, Imeson JD, Meade TW. Phobic anxiety and ischaemic heart disease. BMJ 1987; 295: 297-9.

23 Haynes SG, Feinleib M, Kannel WB. The relationship of psychosocial factors to coronary heart disease in the Framingham Study. III. Eight-year incidence of coronary heart disease. Am J Epidemiol 1980; 111: 37-58.

24 Gafarov VV, Gromova EA, Gagulin IV, Gafarova AV. Study of myocardial infarction risk factors within the framework of the WHO Monica-psychosocial program. Klin Med (Mosk) 2006; 84: 24-6.

25 Gafarov VV, Pak VA, Gagulin IV, Gafarova AV. Personal anxiety and ischaemic heart disease [in Russian]. Ter Arkh 2005; 77: 25-9.

26 Davidson KW, Mostofsky E, Whang W. Don't worry, be happy: positive affect and reduced 10-year incident coronary heart disease: the Canadian Nova Scotia Health Survey. Eur Heart J 2010; 31: 1065-70.

27 Phillips AC, Batty GD, Gale CR, Deary IJ, Osborn D, MacIntyre K, et al. Generalized anxiety disorder, major depressive disorder, and their comorbidity as predictors of all-cause and cardiovascular mortality: the Vietnam experience study. Psychosom Med 2009; 71: 395-403.

28 Holt RI, Phillips DI, Jameson KA, Cooper C, Dennison EM, Peveler RC. The relationship between depression, anxiety and cardiovascular disease: findings from the Hertfordshire Cohort Study. J Affect Disord 2013; 150 84-90.

29 Shirom A, Toker S, Jacobson O, Balicer RD. Feeling vigorous and the risks of all-cause mortality, ischemic heart disease, and diabetes: a 20-year follow-up of healthy employees. Psychosom Med 2010; 72: 727-33.

30 Nabi H, Hall M, Koskenvuo M, Singh-Manoux A, Oksanen T, Suominen S, et al. Psychological and somatic symptoms of anxiety and risk of coronary heart disease: the health and social support prospective cohort study. Bio Psychiatry 2010; 67: 378-85.

31 Eaker ED, Sullivan LM, Kelly-Hayes M, D'Agostino RB, Benjamin EJ. Tension and anxiety and the prediction of the 10-year incidence of coronary heart disease, atrial fibrillation, and total mortality: the Framingham Offspring Study. Psychosom Med 2005; 67: 692-6.

32 Carriere I, Ryan J, Norton J, Scali J, Stewart R, Ritchie K, et al. Anxiety and mortality risk in community-dwelling elderly people. Br J Psychiatry 2013; 203: 303-9.

33 Brenes GA, Kritchevsky SB, Mehta KM, Yaffe K, Simonsick EM, Ayonayon HN, et al. Scared to death: results from the Health, Aging, and Body Composition study. Am J Geriatr Psychiatry 2007; 15: 262-5.

34 Bowlin SJ, Medalie JH, Flocke SA, Zyzanski SJ, Goldbourt U. Epidemiology of intermittent claudication in middle-aged men. Am J Epidemiol 1994; 140: 418-30.

35 Gomez-Caminero A, Blumentals WA, Russo L, Brown RR, Castilla-Puentes R. Does panic disorder increase the risk of coronary heart disease? A cohort study of a national managed care database. Psychosom Med 2005; 67: 688-91.

36 Cohen HW, Gibson G, Alderman MH. Excess risk of myocardial infarction in patients treated with antidepressant medications: association with use of tricyclic agents. Am J Med 2000; 108: 2-8.

37 Hamer M, David BG, Seldenrijk A, Kivimaki M. Antidepressant medication use and future risk of cardiovascular disease: the Scottish Health Survey. Eur Heart J 2011; 32: 437-42.

38 Smoller JW, Allison M, Cochrane BB, Curb JD, Perlis RH, Robinson JG, et al. Antidepressant use and risk of incident cardiovascular morbidity and mortality among postmenopausal women in the Women's Health Initiative study. Arch Intern Med 2009; 169: 2128-39. 
39 Lapane KL, Zierler S, Lasater TM, Barbour MM, Carleton R, Hume AL. Is the use of psychotropic drugs associated with increased risk of ischemic heart disease? Epidemiology 1995; 6: 376-81.

40 Albert CM, Chae CU, Rexrode KM, Manson JE, Kawachi I. Phobic anxiety and risk of coronary heart disease and sudden cardiac death among women. Circulation 2005; 111: 480-7.

41 Batelaan NM, ten Have M, van Balkom AJ, Tuithof M, de Graaf R. Anxiety disorders and onset of cardiovascular disease: the differential impact of panic, phobias and worry. J Anxiety Disord 2014; 28: 252-8.

42 Sareen J, Cox BJ, Clara I, Asmundson GJ. The relationship between anxiety disorders and physical disorders in the U.S. National Comorbidity Survey. Depress Anxiety 2005; 21: 193-202.

43 Roy-Byrne PP, Davidson KW, Kessler RC, Asmundson GJ, Goodwin RD, Kubzansky L, et al. Anxiety disorders and comorbid medical illness. Gen Hosp Psychiatry 2008; 30: 208-25.

44 Hasler G, Gergen PJ, Kleinbaum DG, Ajdacic V, Gamma A, Eich D, et al. Asthma and panic in young adults: a 20 -year prospective community study. Am J Respir Crit Care Med 2005; 171: 1224-30.

45 Nicholl BI, Halder SL, Macfarlane GJ, Thompson DG, O'Brien S, Musleh M et al. Psychosocial risk markers for new onset irritable bowel syndrome - results of a large prospective population-based study. Pain 2008; 137 : 147-55.

46 Laan W, Termorshuizen F, Smeets HM, Boks MP, de Wit NJ, Geerlings MI. A comorbid anxiety disorder does not result in an excess risk of death among patients with a depressive disorder. J Affect Disord 2011; 135: 284-91.

47 Denollet J, Maas K, Knottnerus A, Keyzer JJ, Pop VJ. Anxiety predicted premature all-cause and cardiovascular death in a 10-year follow-up of middle-aged women. J Clin Epidemiol 2009; 62: 452-6.

48 Van Hout HP, Beekman AT, de Beurs E, Comijs H, van Marwijk H, de Haan M, et al. Anxiety and the risk of death in older men and women. Br J Psychiatry 2004; 185: 399-404

49 Mykletun A, Bjerkeset O, Dewey M, Prince M, Overland S, Stewart R. Anxiety, depression, and cause-specific mortality: the HUNT study. Psychosom Med 2007; 69: 323-31.

50 Holman EA, Silver RC, Poulin M, Andersen J, Gil-Rivas V, McIntosh DN. Terrorism, acute stress, and cardiovascular health: a 3-year national study following the September 11th attacks. Arch Gen Psychiatry 2008; 65: 73-80.

51 Ostir GV, Goodwin JS. High anxiety is associated with an increased risk of death in an older tri-ethnic population. J Clin Epidemiol 2006; 59: 534-40.

52 Ringback Weitoft G, Rosen $M$. Is perceived nervousness and anxiety a predictor of premature mortality and severe morbidity? A longitudinal follow up of the Swedish survey of living conditions. J Epidemiol Community Health 2005; 59: 794-8.

53 Smoller JW, Pollack MH, Wassertheil-Smoller S, Jackson RD, Oberman A Wong ND, et al. Panic attacks and risk of incident cardiovascular events among postmenopausal women in the Women's Health Initiative Observational Study. Arch Gen Psychiatry 2007; 64: 1153-60.

54 Yasuda N, Mino Y, Koda S, Ohara H. The differential influence of distinct clusters of psychiatric symptoms, as assessed by the general health questionnaire, on cause of death in older persons living in a rural community of Japan. J Am Geriatr Soc 2002; 50: 313-20.

55 Janszky I, Ahnve S, Lundberg I, Hemmingsson T. Early-onset depression, anxiety, and risk of subsequent coronary heart disease: 37-year follow-up of 49,321 young Swedish men. J Am Coll Cardiol 2010; 56: 31-7.

56 Aberg MA, Waern M, Nyberg J, Pedersen NL, Bergh Y, Aberg ND, et al Cardiovascular fitness in males at age 18 and risk of serious depression in adulthood: Swedish prospective population-based study. Br J Psychiatry 2012; 201: 352-9.

57 De Jonge $P$, Roest AM. Depression and cardiovascular disease: the end of simple models. Br J Psychiatry 2012; 201: 337-8.

58 Nicholson A, Fuhrer R, Marmot M. Psychological distress as a predictor of CHD events in men: the effect of persistence and components of risk. Psychosom Med 2005; 67: 522-30.

59 Moylan S, Jacka FN, Pasco JA, Berk M. Cigarette smoking, nicotine dependence and anxiety disorders: a systematic review of population-based epidemiological studies. BMC Med 2012; 10: 123

60 Falk Dahl CA, Dahl AA. Lifestyle and social network in individuals with high level of social phobia/anxiety symptoms: a community-based study. Soc Psychiatry Psychiatr Epidemiol 2010; 45: 309-17.

61 Jacka FN, Mykletun A, Berk M, Bjelland I, Tell GS. The association between habitual diet quality and the common mental disorders in communitydwelling adults: the Hordaland Health study. Psychosom Med 2011; 73 483-90.
62 Papakostas Gl, Ongur D, losifescu DV, Mischoulon D, Fava M. Cholesterol in mood and anxiety disorders: review of the literature and new hypotheses. Eur Neuropsychopharmacol 2004; 14: 135-42.

63 Player MS, Peterson LE. Anxiety disorders, hypertension, and cardiovascular risk: a review. Int J Psychiatry Med 2011; 41: 365-77.

64 Pitsavos C, Panagiotakos DB, Papageorgiou C, Tsetsekou E, Soldatos C, Stefanadis $C$. Anxiety in relation to inflammation and coagulation markers, among healthy adults: the ATTICA study. Atherosclerosis 2006; 185: 320-6.

65 Von Kanel R, Mills PJ, Fainman C, Dimsdale JE. Effects of psychological stress and psychiatric disorders on blood coagulation and fibrinolysis: a biobehavioral pathway to coronary artery disease? Psychosom Med 2011; 63: $531-44$

66 Young EA, Abelson JA, Liberzon I. Stress hormones and anxiety disorders. In Handbook of Anxiety and Fear (eds DC Blanchard, G Griebel, D Nutt): 455-473. Elsevier, 2008.

67 Vreeburg SA, Zitman FG, van Pelt J, Derijk RH, Verhagen JC, van Dyck R, et al. Salivary cortisol levels in persons with and without different anxiety disorders. Psychosom Med 2010; 72: 340-7.

68 Friedman $\mathrm{BH}$. An autonomic flexibility-neurovisceral integration model of anxiety and cardiac vagal tone. Biol Psychol 2007; 74: 185-99.

69 Licht CM, Penninx BW, de Geus EJ. Effects of antidepressants, but not psychopathology, on cardiac sympathetic control: a longitudinal study. Neuropsychopharmacology 2012; 37: 2487-95.

70 Petticrew M, Davey Smith G. The monkey puzzle: a systematic review of studies of stress, social hierarchies, and heart disease in monkeys. PLOS One 2012; 7: e27939.

71 Watson SL, Shively CA, Kaplan JR, Line SW. Effects of chronic social separation on cardiovascular disease risk factors in female cynomolgus monkeys. Atherosclerosis 1998; 137: 259-66.

72 Dhabhar FS, Saul AN, Holmes TH, Daugherty C, Neri E, Tillie JM, et al. High-anxious individuals show increased chronic stress burden, decreased protective immunity, and increased cancer progression in a mouse model of squamous cell carcinoma. PLOS One 2012; 7: e33069.

73 Lenze EJ, Mantella RC, Shi P, Goate AM, Nowotny P, Butters MA, et al. Elevated cortisol in older adults with generalized anxiety disorder is reduced by treatment: a placebo-controlled evaluation of escitalopram. Am J Geriatr Psychiatry 2011; 19: 482-90.

74 Rice KM, Blanchard EB, Purcell M. Biofeedback treatments of generalized anxiety disorder: preliminary results. Biofeedback Self Regul 1993; 18 93-105.

75 Middleton HC, Ashby M. Clinical recovery from panic disorder is associated with evidence of changes in cardiovascular regulation. Acta Psychiatr Scand 1995; 91: 108-13.

76 Sullivan GM, Kent JM, Kleber M, Martinez JM, Yeragani VK, Gorman JM. Effects of hyperventilation on heart rate and QT variability in panic disorder pre- and post-treatment. Psychiatry Res 2004; 125: 29-39.

77 Licht CM, de Geus EJ, van Dyck R, Penninx BW. Association between anxiety disorders and heart rate variability in The Netherlands Study of Depression and Anxiety (NESDA). Psychosom Med 2009; 71: 508-18.

78 Thombs BD, de Jonge P, Coyne JC, Whooley MA, Frasure-Smith N, Mitchell $\mathrm{AJ}$, et al. Depression screening and patient outcomes in cardiovascular care: a systematic review. JAMA 2008; 300: 2161-71.

79 De Jonge $\mathrm{P}$, Honig A, van Melle JP, schene AH, Kuyper AM, Tulner $D$, et al Nonresponse to treatment for depression following myocardial infarction: association with subsequent cardiac events. Am J Psychiatry 2007; 164: 1371-8.

80 Carney RM, Blumenthal JA, Freedland KE, Youngblood M, Veith RC, Burg MM, et al. Depression and late mortality after myocardial infarction in the Enhancing Recovery in Coronary Heart Disease (ENRICHD) study. Psychosom Med 2004; 66: 466-74.

81 Chida $Y$, Steptoe A. The association of anger and hostility with future coronary heart disease: a meta-analytic review of prospective evidence. J Am Coll Cardiol 2009; 53: 936-46.

82 Bogers RP, Bemelmans WJ, Hoogenveen RT, Boshuizen HC, Woodward M, Knekt $P$, et al. Association of overweight with increased risk of coronary heart disease partly independent of blood pressure and cholesterol levels: a meta-analysis of 21 cohort studies including more than 300000 persons. Arch Intern Med 2007; 167: 1720-8.

83 Gami AS, Witt BJ, Howard DE, Erwin PJ, Gami LA, Somers VK, et al. Metabolic syndrome and risk of incident cardiovascular events and death: a systematic review and meta-analysis of longitudinal studies. J Am Coll Cardiol 2007; 49: 403-14.

84 Li J, Siegrist J. Physical activity and risk of cardiovascular disease - a metaanalysis of prospective cohort studies. Int J Environ Res Public Health 2012; 9: $391-407$ 
85 Kessler RC, Chiu WT, Demler O, Merikangas KR, Walters EE. Prevalence, severity, and comorbidity of 12-month DSM-IV disorders in the National Comorbidity Survey Replication. Arch Gen Psychiatry 2005; 62: 617-27.

86 Batelaan N, Rhebergen D, de Graaf R, Spijker J, Beekman A, Penninx B. Panic attacks as a dimension of psychopathology: evidence for their impact on onset and course of mental disorders and functioning. J Clin Psychiatry 2012; 73: $1195-202$

87 Kessler RC, Chiu WT, Jin R, Ruscio AM, Shear K, Walters EE. The epidemiology of panic attacks, panic disorder, and agoraphobia in the National Comorbidity Survey Replication. Arch Gen Psychiatry 2006; 63: 415-24.

88 Lewinsohn PM, Shankman SA, Gau JM, Klein DN. The prevalence and co-morbidity of subthreshold psychiatric conditions. Psychol Med 2004; 34: 613-22.

89 National Institute for Health and Clinical Excellence. Generalised Anxiety Disorder and Panic Disorder (With or Without Agoraphobia) in Adults: Management in Primary, Secondary and Community Care. Clinical Guideline 113. NICE, 2011.

90 Wang PS, Lane M, Olfson M, Pincus HA, Wells KB, Kessler RC. Twelvemonth use of mental health services in the United States: results from the National Comorbidity Survey Replication. Arch Gen Psychiatry 2005; 62: $629-40$

91 Gustad LT, Laugsand LE, Janszky I, Dalen H, Bjerkeset O. Symptoms of anxiety and depression and risk of acute myocardial infarction: the HUNT 2 study. Eur Heart J 2014; 35: 1394-403.

92 Vaccarino V, Goldberg J, Rooks C, Shah AJ, Veledar E, Faber TL, et al. Post-traumatic stress disorder and incidence of coronary heart disease: a twin study. J Am Coll Cardiol 2013; 62: 970.

93 Chou $\mathrm{PH}$, Lin $\mathrm{CH}$, Loh $\mathrm{E}$, Chan $\mathrm{CH}$, Lan TH. Panic disorder and risk of stroke: a population-based study. Psychosomatics 2012; 53: 463-9.

94 Chen YH, Tsai SY, Lee HC, Lin HC. Increased risk of acute myocardial infarction for patients with panic disorder: a nationwide population-based study. Psychosom Med 2009; 71: 798-804.

95 Jordan HT, Miller-Archie SA, Cone JE, Morabia A, Stellman SD. Heart disease among adults exposed to the September 11, 2001 World Trade Center disaster: results from the World Trade Center Health Registry. Prev Med 2011; 53: 370-6.

96 Scherrer JF, Chrusciel T, Zeringue A, Garfield LD, Hauptman PJ, Lustman PJ, et al. Anxiety disorders increase risk for incident myocardial infarction in depressed and nondepressed Veterans Administration patients. Am Heart 2010; 159: 772-9.

97 Kubzansky LD, Koenen KC, Jones C, Eaton WW. A prospective study of posttraumatic stress disorder symptoms and coronary heart disease in women. Health Psychol 2009; 28: 125-30.

98 Boscarino JA. A prospective study of PTSD and early-age heart disease mortality among vietnam veterans: implications for surveillance and prevention. Psychosom Med 2008; 70: 668-76.
99 Jakobsen $\mathrm{AH}$, Foldager L, Parker G, Munk-Jorgensen P. Quantifying links between acute myocardial infarction and depression, anxiety and schizophrenia using case register databases. J Affect Disord 2008; 109 : 177-81.

100 Walters K, Rait G, Petersen I, Williams R, Nazareth I. Panic disorder and risk of new onset coronary heart disease, acute myocardial infarction, and cardiac mortality: cohort study using the general practice research database. Eur Heart J 2008; 29: 2981-8.

101 Gafarov VV, Gromova HA, Gagulin IV, Ekimova YC, Santrapinskiy DK. Arterial hypertension, myocardial infarction and stroke: risk of development and psychosocial factors. Alaska Med 2007; 49: 117-9.

102 Boyle SH, Michalek JE, Suarez EC. Covariation of psychological attributes and incident coronary heart disease in U.S. Air Force veterans of the Vietnam war. Psychosom Med 2006; 68: 844-50.

103 Kubzansky LD, Cole SR, Kawachi I, Vokonas P, Sparrow D. Shared and unique contributions of anger, anxiety, and depression to coronary heart disease: a prospective study in the normative aging study. Ann Behav Med 2006; 31: 21-9.

104 Thurston RC, Kubzansky LD, Kawachi I, Berkman LF. Do depression and anxiety mediate the link between educational attainment and $\mathrm{CHD}$ ? Psychosom Med 2006; 68: 25-32.

105 Haines A, Cooper J, Meade TW. Psychological characteristics and fatal ischaemic heart disease. Heart 2001; 85: 385-9.

106 Bowen RC, Senthilselvan A, Barale A. Physical illness as an outcome of chronic anxiety disorders. Can J Psychiatry 2000; 45: 459-64.

107 Kawachi I, Colditz GA, Ascherio A, Rimm EB, Giovannucci E, Stampfer MJ, et al. Prospective study of phobic anxiety and risk of coronary heart disease in men. Circulation 1994; 89: 1992-7.

108 Vogt T, Pope C, Mullooly J, Hollis J. Mental health status as a predictor of morbidity and mortality: a 15-year follow-up of members of a health maintenance organization. Am J Public Health 1994; 84: 227-31.

109 Eaker ED, Pinsky J, Castelli WP. Myocardial infarction and coronary death among women: psychosocial predictors from a 20-year follow-up of women in the Framingham Study. Am J Epidemiol 1992; 135: 854-64.

110 Rosengren A, Tibblin G, Wilhelmsen L. Self-perceived psychological stress and incidence of coronary artery disease in middle-aged men. Am J Cardiol 1991; 68: 1171-5.

111 Pearson TA, Blair SN, Daniels SR, Eckel RH, Fair JM, Fortmann SP, et al. AHA Guidelines for Primary Prevention of Cardiovascular Disease and Stroke: 2002 Update: Consensus Panel Guide to Comprehensive Risk Reduction for Adult Patients Without Coronary or Other Atherosclerotic Vascular Diseases. American Heart Association Science Advisory and Coordinating Committee. Circulation 2002; 106: 388-91. 